\title{
The economic value of fire damages in Tuscan agroforestry areas
}

\author{
Claudio Fagarazzi ${ }^{(1)}$, \\ Roberto Fratini ${ }^{(1)}$, \\ Mara Montanino (1), \\ Mauro Viccaro ${ }^{(2)}$, \\ Mario Cozzi ${ }^{(2)}$, \\ Severino Romano ${ }^{(2)}$, \\ Francesco Riccioli ${ }^{(3)}$
}

\begin{abstract}
The Tuscan Region (Central Italy) spends about 12 million euros every year in the prevention and suppression of forest fires. In this context, this study aims to analyse the economic and environmental benefits derived from fire suppression activities. Starting from a case study of a real fire event in Tuscany, we simulated three hypothetical scenarios (with different fire durations) without fire extinction activities planned by using the open source software FARSITE. Benefits derived from fire extinction activities can be quantified as the avoided damage, which has been calculated through the estimation of the total economic value of forests not destroyed by fire thanks to the extinction action. The avoided damage is represented by the difference between values of forest areas burned by the real fire event and those burned by simulated fire. By providing an economic estimation of avoided damages, our results confirm that forest fire services and forest management have a high impact on both the economy and the environment.
\end{abstract}

\section{Keywords: Fire Damage, FARSITE, Total Economic Value, Fire Simulation, GIS}

viability in wild and mountainous areas are the main factors of this phenomenon. Indeed, the trigger point of numerous fires is close to the edge of roads and highways (Martínez et al. 2009).

Despite the increase in the number of fires, the surfaces covered by fire are progressively decreasing in extent. In Italy, in the decade between 1995 and 2005, $1,185,000$ hectares (ha) of surface burned, while 765,000 ha were destroyed by fire in the previous decade (2006-2015), corresponding to a reduction of $35 \%$ (Perelli 2013). The reduction in the area covered by fires in recent years is, above all, the consequence of an improvement in firefighting organization both at regional and national level. In the case of Tuscany, the number of forest fires did actually increase from 2010 to 2015 , but the wooded area covered by the fire significantly decreased. During this period, the number of forest fires rose from 243 to 303 per year, while the average area of individual events declined from 1.56 to 0.75 ha (Perelli 2013).
(1) University of Florence, Department of Agricultural, Food, Environmental and Forestry Sciences and Technologies, p.le delle Cascine 18, I-50144 Firenze (Italy); (2) University of Basilicata, School of Agricultural, Forestry, Food and Environmental Sciences, v. dell'Ateneo Lucano, I-85100 Potenza (Italy); (3) University of Pisa, Department of Veterinary science - rural economic section, v.le delle Piagge 2, I-56124 Pisa (Italy)

@ Francesco Riccioli (francesco.riccioli@unipi.it)

Received: Aug 05, 2020 - Accepted: Nov 12, 2020

Citation: Fagarazzi C, Fratini R, Montanino M, Viccaro M, Cozzi M, Romano S, Riccioli F (2021). The economic value of fire damages in Tuscan agroforestry areas. iForest 14: 41-47. doi: 10.3832/ifor3607-013 [online 2021-01-14]

Communicated by: Rodolfo Picchio
The regional administration of Tuscany invests almost 12 million euro per year in forest fire prevention and repression activities. Despite such significant financial commitment, both the extent of the damage caused to goods and that of the damage avoided thanks to fire prevention and repression are still unclear. Knowing the magnitude of such effects would allow better efficiency and effectiveness of investment planning policies.

Several studies in the literature aimed to assess the damage caused to agroforestry areas by fires (Arca et al. 2009, Di Renzo et al. 2012). This work focus on a methodology aimed to assess the potential evolution of fires in the absence of anthropogenic extinction and to evaluate the resulting avoided damages. Starting from a case study taken from a real event occurred in Tuscany, three different scenarios of wildfire were simulated excluding fire extinction activities. These simulations were implemented in a Geographical Information Systems (GIS) program using the open source software FARSITE (Finney \& Ryan 1995 ) to simulate a fire event (Corona et al. 2014).

Avoided damages are related to forests and the ecosystem services they provide (Viccaro \& Caniani 2019), and include benefits such as recreation and tourist functions, biodiversity conservation, timber production, carbon storage, and hydrogeological conservation. These benefits represent the Total Economic Value (TEV) of the forest and consider both private and public environmental functions. Many studies in the literature have quantified these functions (Tao et al. 2012, Marinelli \& Marone 2013, Chatzinikolaou et al. 2015, Bottalico et al. 2016). In this study, we have calculated the TEV of the area burned during a real 
fire event and the TEV of areas destroyed by simulated fires. Fire extinction activities are planned only in the real event, so the difference between the TEV of simulated events and TEV of the real event represents the avoided damages due to fire ex tinction activities.

The goal of the paper is to quantify the avoided damage by forecast a burned area by simulating a fire event with FARSITE and calculate the corresponding TEV values.

\section{Material and methods}

\section{Case study}

The wildfire examined occurred in Verniano, Colle di Val d'Elsa, near Siena (Tuscany, Central Italy) during the period between July 11 and August 3, 2012 (Fig. 1). The affected area was 308.12 ha. The area is mostly hilly $(66.5 \%)$, with some plains (about $8.4 \%$ of the territory) and major mountain ranges (25.1\% of the region), and annual rainfall of about $600-700 \mathrm{~mm}$.

The fire was certainly arson and caused by pruning residues burned in a farm near the affected area. The deployment of intervention forces was difficult, due to adverse weather conditions that required complex action plans and the intervention of three Canadair firefighting aircrafts over four days.

The area affected by the fire included mixed stands of conifers and broad-leaved trees, with a prevalence of Mediterranean pines and cypresses (domestic pine, maritime pine, Aleppo pine).

The estimated damage of the real fire event is based on the perimeter delineated by firefighters. For determining the costs of extinction or specific costs of the fight, reference was made to studies conducted by the Italian Academy of Forest Sciences in 2007 (Ciancio et al. 2007). In this study, an intermediate approach was applied, based on the detailed definition of unit costs of personnel and equipment, in relation to the National Collective Labour Contracts of the various operators involved (State Forestry Corps, National Fire Corps, etc.) and the hourly costs of the equipment that can be inferred from service contracts, Confindustria (General Confederation of Italian Industry) construction tables and sector bibliography, and technical data sheets. The total cost of fire extinction activities was over 1,222,000 euros.

\section{Simulations of fire}

Simulations of wildfire were performed using the software FARSITE (Fire Area Simulator). FARSITE, developed by Finney \& Ryan (1995), was integrated using a vector propagation technique for fire perimeter expansion that controls both space and time resolution of fire growth over the landscape. FARSITE is a deterministic fire growth model using a vector propagation technique to simulate fire perimeter expansion over a heterogeneous landscapewhere the simulation results can be directly compared to inputs. FARSITE is an efficient tool for simulating fire spread across a landscape as it accounts for the variability of fuel moisture, wind speed and direction over time and space. This is a powerful system suitable to simulate ground and air suppression actions in order to identify a set of comparable scenarios and results. In particular, the FARSITE was recently implemented in the FlamMap software (https:// www.firelab.org/project/flammap).
Fig. 1 - The study area in Verniano, Tuscany (Central Italy).

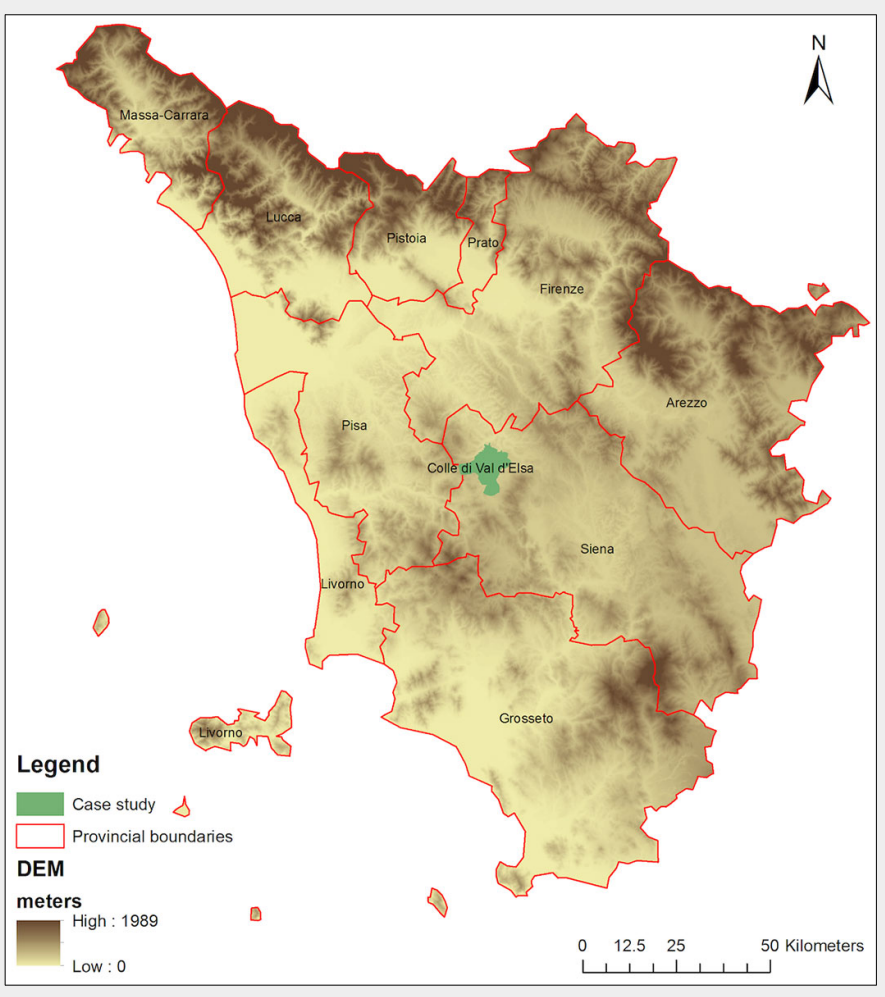

The new FlamMap is able to model the potential fire behavior (spread rate, flame length, fireline intensity, etc.) under constant environmental conditions (weather and fuel moisture). In particular, thanks to the inclusion of FARSITE, the software can compute wildfire growth and behavior for longer time periods under heterogeneous conditions of terrain, type of fuels, fuel moistures and weather.

The FlamMap algorithm calculates the minimum fire travel time between nodes over a gridded landscape relying upon the spatial variability of fuels and topography to drive fire growth. However, FlamMap algorithm is not a complete fire growth simulation model like FARSITE. Despite this limitation, FlamMap will be evaluated to determine if it might offer computational advantages over FARSITE in an operational forecast setting (Finney 2004, 2006).

Furthermore, the FARSITE was recently implemented with FlamMap in the Wildland Fire Decision Support System able to support fire officers in tactical and strategic management decisions in the long-term (up to 14 day). In detail, the model produces vector fire perimeters at specified time intervals; the vertices of these polygons contain information which is then in terpolated to produce raster maps of fire behaviour.

The vector modelling approach proved to be a practical technique for incorporating separate models for surface fire, crown fire, acceleration, spotting, and fuel moisture. The model integration was relatively straightforward because the one-dimensional calculations for each model apply directly to the vertices on the fire front.

The semi-empirical propagation model of Rothermel's grazing fire is based on statistical observations of the fire phenomenon under controlled conditions, combined with physical considerations of the combustion event. It derives from the correction of the Frandsen equation of 1971 (Sugihara et al. 2006) and is calculated as the amount of heat received from the vegetal fuel in the numerator, the denominator being the amount of heat necessary to bring the fuel to the ignition temperature (eqn. 1):

$$
R=\frac{I_{x i g}+\int_{-\infty}^{0}\left(\frac{\partial Z_{c}}{\partial Z}\right)_{Z_{c}} d x}{\rho_{b e} Q_{i g}}
$$

where $R$ is the quasi-steady state rate of spread, $I_{\text {xig }}$ is the horizontal propagating heat flux, the value $\left(\partial z_{d} / \partial z\right)_{z c}$ represents the gradient of the vertical intensity flux, $\rho_{\text {be }}$ is the effective bulk density and $Q_{\text {ig }}$ is the heat of pre-ignition.

In the literature, the FARSITE software has been applied to enhance data assimilation capabilities on both fire perimeters and fuel adjustment factors, thus improving the accuracy of fire spread predictions. Srivas et al. (2017) used the "Ensemble Kalman Filter" (EnKF) to extend FARSITE with data assimilation capabilities to up- 
date both fire perimeters and fuel adjustment factors. Zhou et al. (2019) tested an extension of EnKF called Ensemble transform Kalman Filter (ETKF) which avoids using perturbed observations to eliminate additional sampling errors.

The FARSITE outputs illustrate the strict spatial consequences of fire behaviour by incorporating the models into a two-dimensional simulation. Simplified test conditions show that surface fire growth and intensity conform to idealized patterns. Similarities also exist between simulated crown fires and observed patterns of extreme wind-driven fires. According to Finney \& Ryan (1995), the model generates complex patterns of fire growth and behaviour based on spatial and temporal dependencies. On the other hand, the FARSITE model requires uniform conditions (in space and time) of the factors affecting fire (fuels, weather, and topography) over the wildfire area, although these conditions rarely exist in nature.

The input of the model included several data layers which can be grouped in three main categories: (i) landscape data; (ii) weather data; and (iii) fuel data.

(i) Landscape data include the digital elevation model, slope, canopy cover, and fuel type. To ensure a good representation of the FARSITE model in the Italian context, we defined the fire growth of individual fuel types by reclassifying land uses as fuel type codes which reflect the susceptibility to burning of each land use. To this purpose, the 1972 Rothermel model was modified in order to match the CLC (Soil Corine Land Cover 2012 level V, ver. 18.5.1) classes and the Rothermel Fuel Model classes (Rothermel 1972).

(ii) Weather data (start-end precipitation, $\mathrm{min} / \mathrm{max}$ temperature, $\mathrm{min} / \mathrm{max}$ humidity, etc.) and data of the event (such as ignition point, direction, wind speed, etc.) were obtained from LAMMA (2020). Each parameter was georeferenced using a pixel resolution of 10 meters.

(iii) Fuel files data are related to characteristics of land use such as crown bulk density, crown base height, foliar moisture content, stand height, etc.

Combining the above-mentioned data in the FARSITE input, three different scenarios were simulated which differed in the duration of the wildfire event without fire extinction activities: (i) Simulation $0=$ same duration of the real event in Verniano; (ii) Simulation $1=7$ days more than the duration of the real event; (iii) Simulation $2=14$ days more than the duration of the real event.

\section{Evaluation of total economic value}

Forest produces both private goods (timber production, non-wood products) and public utility services (recreational activities, hydrogeological function, biodiversity protection, $\mathrm{CO}_{2}$ storage, etc.). Considering fire damages, the multifunctional role of forest introduces a significant problem re- lated to the compensation of two subjects involved: private owners for damage suffered by their incomes, and public owners for damage to ecosystem services. We computed the avoided damage due to fire extinction activities by quantifying the ecosystem function/services provided by the forest. These benefits represent the Total Economic Value (TEV) of the forest considering both private and public environmental functions, including incomes (e.g., climate change mitigation service, wood production, etc.).

Regarding the degree of damage and the intensity of the event, the proposed approach requires to set some initial hypotheses. First, it is assumed that the damage to the forest is total, not partial; second, we hypothesized that the effects on private and public functions are temporary and therefore all functions can be restored after a recovery time.

Several authors in the literature analysed the damage to forests through the quantification of the TEV. Di Renzo et al. (2012) underline that the determination of the damage and its compensation cannot disregard the various components that contribute to the total economic value of the forest area. Specifically, they define the damage of private interest as those ascribable to the forest topsoil, to the structures and infrastructures, while those of public interest are represented by damages to all those goods and resources providing services of public interest which were compromised after the wildfire.

A wide literature provides a schematic classification of TEV. Pearce (2001) and Polelli (2008) divide TEV into two macrocategories (Use Value and Non-Use Value). Moreover, they are subdivided into Direct Value, Indirect Value, Option value, Existence Value and Bequest Value categories. In this study, the approach proposed by Bernetti et al. (2011), Bernetti et al. (2013) and Marinelli \& Marone (2013) has been adopted for TEV estimation. These authors provided a quantification of TEV (in euros ha $^{-1}$ per year) by using a territorial approach where the TEV value of all forests in Tuscany have been georeferenced.

The following functions have been considered in this study: (i) tourist-recreational function; (ii) naturalistic function; (iii) hydrological function; (iv) drinking water service; (v) timber production; (vi) carbon sequestration.

The recreational tourist function is given by the sum of recreational tourism activity, hunting activity and mushroom collecting activity. The first activity was estimated using the Travel Cost Method (TCM) with specific logit models for naturalistic areas (Ferrini 2002). The recreational value was obtained using the Random Utility Travel Cost Method (RUTCM) proposed by Ferrini (2002) and considering different variables (e.g., age, education, etc.). This method has been employed to assess multivariate demand functions in protected areas. In this case, the variation of the consumer surplus was evaluated following an increase of $10 \%$ of the surface for 19 natural parks in Tuscany (Ferrini 2002). Hunting activities were evaluated based on the willingness-to-pay of hunters, according to Marinelli \& Romano (1997). The updated result has been correlated with the number of active hunters in Tuscany, which is equal to 520.77 euros ha $^{-1}$ per year per hunter multiplied by all hunters of Tuscany $(111,827)$ in the year 2012. Finally, the recreational function (mushroom collection) was calculated based on the maximum value for the authorization to mushroom picking ( 15 euros per day) provided by regional law no. 16/1999. This value was multiplied by the number of persons collecting mushroom $(461,093)$ and the average picking day per person (5).

Natural functions were calculated according to literature reviews (Fisher \& Raucher 1984, Boyle \& Bishop 1987) based on the willingness-to-pay (in euros per family per year) for biodiversity, ecological value and endangered species.

The water flow service was estimated based on the refurbishment costs that would be necessary to pay in order to guarantee the maximum flow rates in the $a b$ sence of the forest. In particular, considering run-off index and aridity index of each basin (Marinelli \& Marone 2013, Riccioli et al. 2019a), a maximum sizing of the expansion tank system was necessary to ensure the disposal of the increase inflow due to the absence of forest and to calculate the total annualized cost of the system of boxes. Finally, this subrogation cost was attributed to each "pixel" of the basins proportionally to the quantity of water governed by the presence of the forest.

The drinking water service was assessed by hypothesizing that the best alternative to groundwater is represented by the water reserves stored in artificial basins and the consequent contribution of forest soils to the production of drinking water calculated using the water balance method. In this case, the values of water storage in the watersheds in Tuscany were defined based on the studies carried out by Civita et al. (1999). The process was achieved in two steps. First, the water balance of a single forest location was calculated using the method of the reversed water balance. Then, to calculate the drinking water service value, the subrogation price per cubic meter was applied.

Timber production was calculated by converting the capital value of the forest, obtained with the classic Faustmann formula, into a yearly value. According to the methodology reported in Fagarazzi et al. (2009) and Fagarazzi \& Tirinnanzi (2015), we considered data related to stumpage value (associated to the production processes, the forestry and harvesting activities), the ecological characteristics (increments, type of wood, etc.), and other variables (distance from the market centers, productivity, ma- 
Tab. 1 - Total Economic Value (TEV) of each forest function/service calculated over all the Tuscany region (data expressed in euros $\mathrm{yr}^{-1}$ ).

\begin{tabular}{lr}
\hline Function/Service & \multicolumn{1}{c}{ Value } \\
\hline $\begin{array}{l}\text { Recreational/tourist } \\
\text { function }\end{array}$ & $219,860,253$ \\
\hline Naturalistic function & $210,043,738$ \\
\hline Water flow control & $28,224,320$ \\
\hline Drinking water service & $59,382,140$ \\
\hline Wood production & $25,116,257$ \\
\hline $\begin{array}{l}\text { Climate change } \\
\text { mitigation service }\end{array}$ & $59,017,484$ \\
\hline TEV & $601,644,192$ \\
\hline
\end{tabular}

chine costs, etc.).

Finally, the climate change mitigation service was quantified by assessing the carbon stored in the trees (and therefore not released into the atmosphere) which is related to tree growth. The calculation was based on the biomass expansion factor

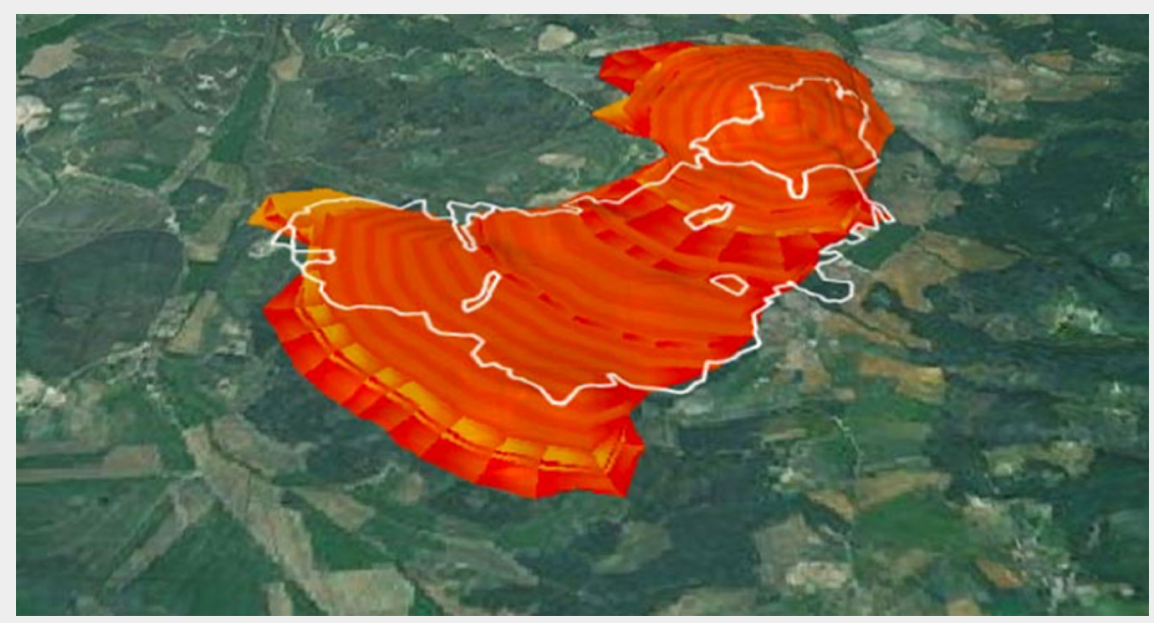

Fig. 2 - Extension of the area burned during the real fire event (in white) and that simulated under the "Scenario o" (no fire suppression, same duration).

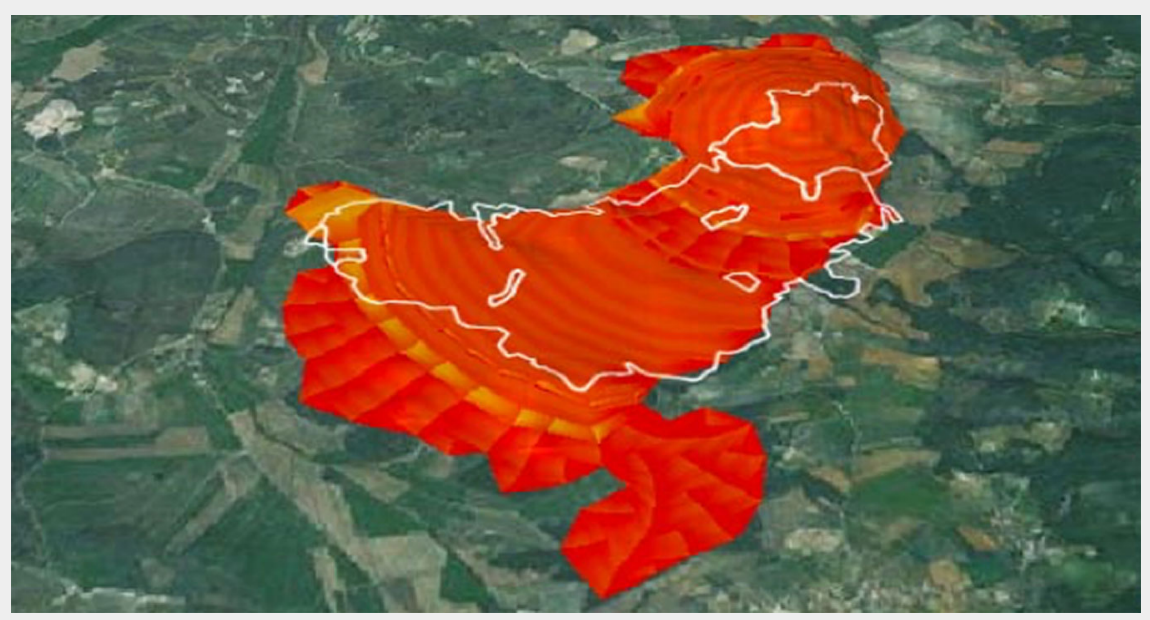

Fig. 3 - Extension of the area burned during the real fire event (in white) and that simulated under the "Scenario 1" (no fire suppression, +7 days duration).
(BEF) to quantify the annual quantity of carbon fixed in the trees (Romano et al. 2015, Riccioli et al. 2019b).

All technical parameters, data source and in Appendix 1 of Bernetti et al. (2013).

\section{Evaluation of avoided damage}

The economic damage which was avoided thanks to fire suppression activities was quantified using the above-mentioned TEV.

TEV was calculated for each pixel falling within the burned area both during the real event and for each of the three simulated $T E V_{i k}=\sum_{j=1}^{N} F_{j k}$

where $\mathrm{TEV}_{\mathrm{ik}}$ is the TEV of $i$-th event (real event: $r$, or simulated fire: $s$ ) of $k$-th pixel (burned surface), $F_{i k}$ is the value of $j$-th function belonging to the $k$-th pixel (burned surface), and $\mathrm{N}$ is the total number of functions examined.

Previous studies have considered separately the different forest functions/ser- vices (Romano et al. 2015, Bottalico et al. 2016, Riccioli et al. 2019c). In this work, we made the implicit assumption that the values estimated for each function at each pixel considered can be summed up in eqn. 2, despite different species, stand age, and forest type (coppice or high forest) were included in the analysis.

The overall TEV quantified over the Tuscany region is shown in Tab. 1, expressed in euros year-1.

The avoided damage (AD) is represented by the TEV calculated only on the areas preserved from fire (unburned) thanks to the fire extinction activities. For this purpose, the fire growth simulation model was run for a duration equal to that of the real fire (as recorded in the intervention sheet) in order to verify which areas have been preserved thanks to fire suppression interventions (Simulation o). Additional simulations were performed based on the scenario of no fire suppression, with a fire duration of one (Simulation 1) and two (Simulation 2) additional weeks. The avoided damage due to fire extinction activities has thus been estimated by the difference between the TEV of the simulated fire (no fire suppression) and the TEV of the real event (where fire suppression took place), using the following formula (eqn. 3):

$$
A D_{k}=T E V_{s k}-T E V_{r k}
$$

where $A D_{k}$ is the avoided damage of $k$-th burned surface, TEVs $s_{k}$ is the TEV of simulated fire in $k$-th burned surface (fire extinction activities not planned), and $T E V_{r k}$ is the TEV of real event occurred in $k$-th burned surface (fire extinction activities planned).

\section{Results and discussion}

\section{Simulated fires}

Fig. 2, Fig. 3 and Fig. 4 show the results of the wildfire simulation model imposing different fire durations. The 3D images highlight how geomorphology and land use heavily affected the evolution of the fire; for matters of comparison, the boundary of the area interested by the real fire event is drawn in white, while the extent of the burned area obtained from the three simulations (Simulation 0: same duration of the real event; Simulation 1: +7 days; Simulation 2: +14 days) are depicted in red.

The surface destroyed by fire in Simulation o (Fig. 2) has an extension of 500 ha, almost matching the boundaries of the real event that occurred on the ground. An exception is represented by the area situated in the top part of Fig. 2, which was not interested by the wildfire. In this area, there are residential and tourist buildings that the extinction activities had successfully protected. The surface destroyed by fire in Simulation 1 (Fig. 3) has an extension of 600 ha, while in simulation 2 (Fig. 4) the burned area covers 620 ha; this fire destroyed a large portion of agricultural land, therefore slowing down the flame front. 
The simulation results show that the fire slightly extend in south-west direction, while its perimeter remains almost unchanged in the other directions. By comparing the results of Simulations 1 and Simulation 2, it is possible to note that the difference in the burned area is only 20 hectares; this probably reflects the presence of crop fields, which during summer would not have represented a sufficient source of fuel to further support the spread of fire.

\section{Economic evaluation of the avoided damage}

The TEV of areas destroyed by the real fire event (which had been controlled by fire suppression activities) is equal to 51,660 euro per year (sum of $j$-th function belonging to the $k$-th burned surface). The TEV of areas affected by the three simulated fires is 66,197 euro per year in the case of simulation 0 (the same fire duration as the real event), 70,671 euro per year in the case of simulation 1 ( +7 days fire duration) and 70,700 euro per year in the case of simulation $2(+14$ days fire duration). In all simulated scenarios, fire extinctions activities were not planned.

The avoided annual damage estimated by eqn. 3 were: (i) Simulation $0=14,537$ euros per year (28.1\% of real TEV); (ii) Simulation 1 = 19,011 euros per year (36.8\% of real TEV); (iii) Simulation $2=19,040$ euros per year (36.8\% of real TEV).

It is important to note that on the $8^{\text {th }}$ day after fire ignition the fire front reached rocky and clayey areas poor in fuel, thus it seems plausible to hypothesize that the wildfire would likely be estinguished anyway due to fuel depletion.

The recovery time of forest stands and the restoration of ecosystem functions depends on many variables; in particular, it is strongly influenced by the tree species and the turnover of forest management (coppice or high forest). However, during recovery, the annual value of the forest functions is lost. According to Michieli \& Cipollotti (2018) and Gallerani et al. (2011), the TEV of areas covered by fires was calculated considering the restoring time and the discount rate for economic estimation of monetary values as follows (eqn. 4):

$$
A A D_{k}=A D_{k} \frac{q^{n}-1}{r q^{n}}
$$

where $A A D_{k}$ is the accumulation of avoided

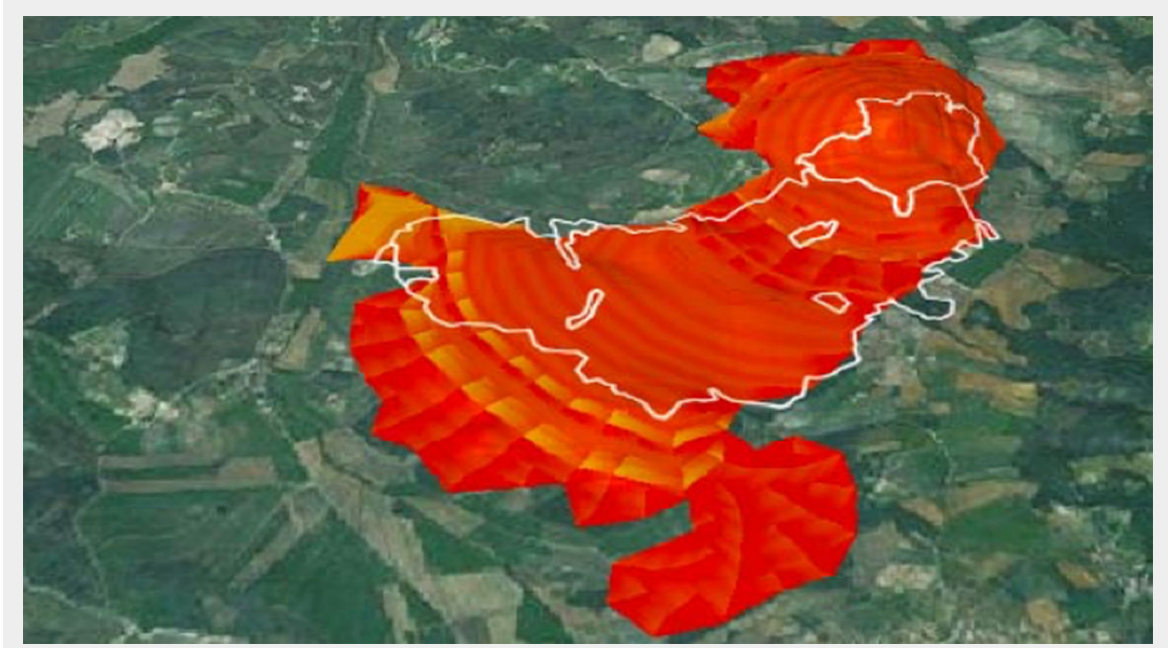

Fig. 4 - Extension of the area burned during the real fire event (in white) and that simulated under the "Scenario 2" (no fire suppression, +14 days duration).

Tab. 2 - Estimated values of damage avoided due to fire suppression activities under different scenarios (different duration of the fire event).

\begin{tabular}{lccc}
\hline Event & $\begin{array}{c}\text { TEV } \\
\left(€ \mathrm{yr}^{-1}-\text { eqn. 1) }\right.\end{array}$ & $\begin{array}{c}\text { Annual } \\
\text { avoided damage } \\
\left(\mathrm{AD}, € \mathrm{yr}^{-1}-\text { eqn. 2) }\right.\end{array}$ & $\begin{array}{c}\text { Accum. of } \\
\text { avoided damage } \\
\left(\mathrm{AAD}, € \mathbf{2 0 y r}^{-1}-\text { eqn. 3) }\right.\end{array}$ \\
\hline Real & 51,660 & - & - \\
\hline Scenario 0 & 66,197 & 14,537 & 237,701 \\
\hline Scenario 1 & 70,671 & 19,011 & 310,857 \\
\hline Scenario 2 & 70,700 & 19,040 & 311,331 \\
\hline
\end{tabular}

damage of $k$-th burned surface in restoring time, $A D_{k}$ is the annual avoided damage of $k$-th burned surface, $q=1+r$, being $r$ the discount rate and $n$ the restoring time. The results are shown in Tab. 2.

As argued by Malczewski (2004), analyses related to natural resources are characterized by a certain degree of uncertainty that is often related to the choice of the market discount rate (Adger et al. 1995, Ciancio et al. 2007). Therefore, in order to choose discount rate and restoring time, a sensitivity analysis has been conducted to assess the accumulation of TEV. The sensitivity analysis was performed considering a fixed discount rate over time and keeping all other factors fixed at their nominal value. Also, the turnover of forest management (restoring time) was considered in this analysis. Setting 2012 as the year zero (the date of fire), five temporal scenarios were considered (20, 40, 60, 80 and 100 years). The different time scenarios are related to the shift (turnover) of the forest species (Quercus ilex) and the forest management system used (high forest). For the discount rate, a range between $1 \%$ and $8 \%$ was considered (Ciancio et al. 2007, Nordhaus 2007, Bottalico et al. 2016.).

Tab. 3 shows the results of the sensitivity analysis carried out considering the annual avoided damage (AD) of the Simulation 0 scenario (14,537 euro per year).

\section{Conclusions and final remarks}

The Tuscan Region spends about 12 million euros every year in the prevention and suppression of forest fires. In this context, this study has analysed the economic and environmental benefits derived from the activities of fire suppression.

Regarding the extinction activities, a monetary approach for the quantification of direct damage "avoided" to the environ-

Tab. 3 - Sensitivity analysis of TEV for "Scenario o" (data expressed in euros).

\begin{tabular}{|c|c|c|c|c|c|c|c|c|}
\hline \multirow{2}{*}{$\begin{array}{l}\text { Restoring } \\
\text { time }\end{array}$} & \multicolumn{8}{|c|}{ Discount rate } \\
\hline & $1 \%$ & $2 \%$ & $3 \%$ & $4 \%$ & $5 \%$ & $6 \%$ & $7 \%$ & $8 \%$ \\
\hline 20 & $262,328.20$ & $237,700.79$ & $216,273.85$ & $197,562.57$ & $181,163.15$ & $166,738.24$ & $154,005.19$ & $142,726.41$ \\
\hline 40 & $477,317.83$ & $397,666.60$ & $336,019.44$ & $287,727.55$ & $249,441.64$ & $218,728.02$ & $193,803.05$ & $173,348.10$ \\
\hline 60 & $653,511.39$ & $505,319.01$ & $402,319.67$ & $328,877.67$ & $275,175.08$ & $234,938.67$ & $204,087.58$ & $179,917.93$ \\
\hline 80 & $797,909.85$ & $577,765.99$ & $439,028.50$ & $347,658.05$ & $284,873.75$ & $239,993.23$ & $206,745.29$ & $181,327.48$ \\
\hline 100 & $916,250.81$ & $626,520.74$ & $459,353.29$ & $356,229.17$ & $288,529.07$ & $241,569.27$ & $207,432.10$ & $181,629.89$ \\
\hline
\end{tabular}


mental components and anthropic activities has been applied. In particular, the difference between the TEV of fire events simulated by FARSITE and the TEV of the real event represents the avoided damages due to fire suppression activities. For this reason, the fire growth simulation model is particularly important to define the surfaces preserved from fire thanks to the fire suppression intervention. The inclusion of different variables (e.g., land use, meteorological conditions, type of fuel) in the FARSITE models allowed to define the spatial and temporal dynamics of fire in a case study located in the province of Siena (central Italy).

It is important to highlight that the observed results are strictly related to the specific fire event occurred in the case study area, as each wildfire is obviously different. Nonetheless, the methodology applied in this study could be adopted in other contexts in order to map the fire events both in a specific area (municipality, province, region, etc), in a specific period (days, weeks, months, etc.) and/or under specific weather conditions.

All data used in this study have been georeferenced with a high level of detail (pixel resolution: $10 \times 10 \mathrm{~m}$ ) using a Geographical Information System. The use of high-resolution georeferenced data represents a new frontier in spatial territorial planning, as argued by Zandersen \& Tol (2009), Bernetti et al. (2011), Baerenklau et al. (2010), Bottalico et al. (2016) and Cozzi et al. (2019).

The main drawback of this study relies in the implicit assumption that the values estimated for each ecosystem function/service at each pixel can be added up together to quantify the TEV. This can be overcome in different ways in future studies. Nonetheless, the monetary quantifications of ecosystem services allowed to analyse fire damages from an economic and environmental point of view. Indeed, we highlighted the potential loss of the economic value of ecosystem services due to fire. Combining the information on the TEV in different fire scenarios based on simulations, we were able to quantify the damage avoided by fire suppression activities, which was equal to 14,537 euros year-1 for the Simulation o scenario, i.e., $23 \%$ of TEV of the real condition.

The sensitivity analysis carried out allowed to forecast the future revenues that could be lost due to fire. This analysis provides different results using different temporal scenarios and different discount rates. The aim is to guide stakeholders towards an optimal planning decision.

In the case study, the fire suppression activities were characterized by a massive use of men and airplanes in the first four days to avoid fire propagation towards an inhabited area, and this justifies the high fire suppression costs. It is important to highlight how public goods have no effect on high suppression costs. The sequence of extinction activities and their intensity is listed in all operating manuals (Anonymous 2011): first protect people, then things (e.g., houses, stables, agricultural outbuildings, etc.), and then forests. Consequently, they are attributed a significant economic and territorial protection value. It is important to stress that, despite the high annual costs of maintenance, the activities of fire prevention and suppression provide economic benefits related to the defense of environmental functions/services as well as private goods, like residential and touristic buildings and farms, which are fairly common in the rural areas of Tuscany.

Regarding the FARSITE model used in this study, the main weakness is the large amount of meteorological data necessary to apply the model to a specific area. However, the model does not consider the "management" choices of the coordinator of fire suppression operations, which deeply affects the fire extinction time and consequently the fire damage.

This study represents a first step to support the economic sustainability of fire extinction activities, and offers a useful basis to further improve the choice of correct planning strategies based on sustainable management of natural areas, as argued by Viccaro et al. (2019) and Riccioli et al. (2020). Future improvements of the methodology applied in this study should focus on the accumulation of the annual TEV of forest considering an accurate restoring time, which could be differentiated by the type of function and silvicultural system (coppice or hight forest). In this way, it will be possible to define the restoring process as a gradual function, whilst in our model the environmental functions/services are completely restored all at once at year 20 . Moreover, an extension of the wildfires sampled and an improvement of the fuel model are desirable in future works.

\section{References}

Adger WN, Brown K, Cervigni R, Moran D (1995). Total economic value of forests in Mexico. Ambio 24 (5): 286-296. [online] URL: http://www. jstor.org/stable/4314349

Anonymous (2011). La lotta attiva agli incendi boschivi: manuale per la formazione di base dell'operatore di una squadra AIB. [Active forest firefighting: AIB Team Operator Basic Training Manual]. Regione Toscana - Giunta regionale, Direzione Generale, Centro stampa Giunta Regione Toscana, Florence, Italy, 1-81. [in Italian]

Arca B, Bacciu V, Duce P, Pellizzaro G, Salis M, Spano D (2009). Simulazione della propagazione degli incendi su vegetazione a macchia mediterranea [Simulation of the propagation of fires on mediterranean spot vegetation]. Collana Ricerca Trasferimento Innovazione, no. 8, Regione Toscana ed., Florence, Italy, pp. 7984. [in Italian]

Baerenklau KA, Gonzàlez-Cabàn A, Paez C, Chavez E (2010). Spatial allocation of forest recreation value. Journal of Forest Economics 16: 113-126. - doi: 10.1016/j.jfe.2009.09.002

Bernetti I, Alampi Sottini V, Marinelli N, Marone
E, Menghini S, Riccioli F, Sacchelli S, Marinelli A (2013). Quantification of the total economic value of forest systems: spatial analysis application to the region of Tuscany (Italy). Aestimum no. 62, Firenze University Press, Florence, Italy, pp. 29-65.

Bernetti I, Marinelli A, Riccioli F (2011). L'allocazione spaziale del beneficio turistico-ricreativo del bosco [The spatial allocation of the recreational-tourist benefit of the forest]. Aestimum no. 59, Firenze University Press, Florence, Italy, pp. 87-104. [in Italian]

Bottalico F, Pesola L, Vizzarri M, Antonello L, Barbati A, Chirici A, Corona P, Cullotta S, Garfi V, Giannico V, Lafortezza R, Lombardi F, Marchetti M, Nocentini S, Riccioli F, Travaglini D, Sallustio $L$ (2016). Modeling the influence of alternative forest management scenarios on wood production and carbon storage: a case study in the Mediterranean region. Environmental Research 144: 72-87. - doi: 10.1016/j.env res.2015.10.025

Boyle K, Bishop R (1987). Valuing wildlife in benefit cost analysis: a case study involving endangered species. Water Resources Research 23: 943-950. - doi: 10.1029/WR023i0o5poog43

Cammelli F, Angelsen A (2019). Amazonian farmers' response to fire policies and climate change. Ecological Economics 165: 106359. doi: 10.1016/j.ecolecon.2019.106359

Chatzinikolaou P, Viaggi D, Raggi M (2015). The evaluation of ecosystem services production: an application in the Province of Ferrara. Biobased and Applied Economics 4 (3): 235-259. [online] URL: http://ageconsearch.umn.edu/re cord/231940/

Ciancio O, Corona P, Marinelli M, Pettenella D (2007). Metodologia per la valutazione economica dei danni da incendi boschivi [Methodology for the economic evaluation of forest fire damage]. Accademia Italiana di Scienze Forestali, Florence, Italy, pp. 5-127. [in Italian]

Civita M, De Maio M, Vigna B (1999). Una metodologia GIS per la valutazione della ricarica attiva degli acquiferi [A GIS methodology for the evaluation of active recharge of aquifers]. In: Proceeding of the Conference "III Convegno Nazionale sulla Protezione e Gestione delle Acque Sotterranee". Parma (Italy) 13-15 Oct 1999. Pitagora, Bologna, Italy, pp. 1291-1303. [in Italian]

Corona P, Ferrari B, Cartisano R, Barbati A (2014). Calibration assessment of forest flammability potential in Italy. iForest - Biogeosciences and Forestry 7: 300-305. - doi: 10.3832/ ifor1123-007

Cozzi M, Prete C, Viccaro M, Romano S (2019). Impacts of wildlife on agriculture: a spatialbased analysis and economic assessment for reducing damage. Natural Resources Research 28: 15-29. - doi: 10.1007/s11053-019-09469-6 Di Renzo F, Fratini R, Marchi E (2012). Stima dei danni da incendio sui Monti Pisani [Estimate of fire damage in the Monti Pisani]. Sherwood 187: pp. 9-14. [in Italian]

Fagarazzi C, Bernetti I, Sacchelli S, Ciampi C (2009). I comparti forestale e di prima trasformazione del legno [The forest sector and first transformation of wood]. In: "Stima della potenzialità produttiva delle agrienergie in Toscana” (Bernetti I, Fagarazzi C, Sacchelli S, Ciampi 
C, Ragaglini G, Villani R, Triana F, Tozzini C, Bonari E eds). ARSIA - Regione Toscana ed., Florence, Italy, 43-76. [in Italian]

Fagarazzi C, Tirinnanzi A (2015). Strumenti per lo sviluppo di filiere biomassa energia di qualità: approcci operativi per garantire la sostenibilità ambientale e sociale [Tools for the development of quality biomass energy supply chains: operational approaches to ensure environmental and social sustainability]. Pacini ed., Lucca, Italy, pp. 1-294. [in Italian]

FAO (2011). Community-based fire management: a review. Forestry Paper, FAO, Rome, Italy, pp. 1-81.

Ferrini S (2002). La domanda di ricreazione all'aperto in parchi e riserve della Toscana [The demand for outdoor recreation in parks and reserves in Tuscany]. Aestimum no. 40, Firenze University Press, Florence, Italy, pp. 41-56.

Finney MA, Ryan KC (1995). Use of the FARSITE fire growth model for fire prediction in US National Parks. In: Proceeding of the Conference "The International Emergency Management and Engineering". Sofia Antipolis (France) 9-12 May 1995. Society for Computer Simulations, S. Diego, CA, USA, pp. 183-189.

Finney MA (2004). Landscape fire simulation and fuel treatment optimization. In: "Methods for Integrating Modeling of Landscape Change: Interior Northwest Landscape Analysis System" (Hayes JL, Ager AA, Barbour JR eds). General Technical Report PNW-GTR-610, USDA Forest Service, Pacific Northwest Station, Portland, OR, USA, pp. 117-131. [online] URL: http://books. google.com/books?id=IJ/4Qt2nzm8C

Finney MA (2006). An overview of FlamMap fire modeling capabilities. In: Proceeding of the Conference "Fuels Management: How to Measure Success". Portland (OR, USA) 28-30 March 2006. Proceedings RMRS-P-41, USDA Forest Service, Rocky Mountain Research Station, Fort Collins, CO, USA, pp. 213-220. [online] URL: http://www.fs.usda.gov/treesearch/pubs/25948 Fisher A, Raucher R (1984). Intrinsic benefits of improved water quality: conceptual and empirical perspectives. In: "Advances in Applied Micro-economics", vol. 3 (Smith VK ed). JAI Press, Greenwich, UK, pp. 37-66.

Gallerani V, Viaggi D, Zanni G (2011). Manuale di estimo [Appraisal Manual] ( $2^{\text {nd }}$ edn). McGrawHill, New York, USA, pp. 1-400. [in Italian]

Garbolino E, Sanseverino-Godfrin V, HinojosMendoza G (2019). Describing and predicting of the vegetation development of Corsica due to expected climate change and its impact on forest fire risk evolution. Safety Science 88: 180186. - doi: 10.1016/j.ssci.2016.02.006

LAMMA (2020). Report metereologici [Metereological reports]. Web site. [in Italian] [online] URL: http://www.lamma.rete.toscana.it/clima-e -energia/climatologia/report-mensili-toscana
Malczewski J (2004). GIS-based land-use suitability analysis: a critical over-view. Progress in Planning 62 (1): 3-65. - doi: 10.1016/j.progress. 2003.09.002

Marinelli A, Romano A (1997). La valutazione economica dei benefici e dell'impatto aggregato della caccia nella provincia di Firenze [The economic evaluation of the benefits and aggregate impact of hunting in the province of Florence]. Giunti ed., Firenze, Italy, pp. 1-280. [in Italian]

Marinelli A, Marone E (2013). Il valore economico totale dei boschi della Toscana [The total economic value of the forests of Tuscany]. Agricoltura e benessere, Franco Angeli ed., Milano, Itay, pp. 1-128. [in Italian]

Martínez J, Vega-Garcia C, Chuvieco E (2009). Human-caused wildfire risk rating for prevention planning in Spain. Journal of Environmental Management 90 (2): 1241-1252. - doi: 10.1016/ j.jenvman.2008.07.005

Michieli I, Cipollotti B (2018). Trattato di estimo [Appraisal treaty]. Edagricole - New Business Media ed., Milano, Italy, pp. 1-720. [in Italian]

Nordhaus W (2007). Critical assumptions in the stern review on climate change. Science 317: 201-202. - doi: 10.1126/science.1137316

Pearce D (2001). The economic value of forest ecosystems. Ecosystem Health 7 (4): 284-296. doi: 10.1046/j.1526-0992.2001.01037.x

Perelli F (2013). Rapporto incendi boschivi [Forest fire report]. Fare, Web site. [in Italian] [online] URL: http://ita.calameo.com/read/0023154 $073029 f 489 f 82 e$

Polelli M (2008). Nuovo trattato di estimo [New appraisal treaty]. Maggioli ed., Sant'Arcangelo di Romagna, Rimini, Italy, pp. 1-1087.

Riccioli F, Gabbrielli E, Casini L, Marone E, El Asmar JP, Fratini R (2019a). Geographical analysis of agro-environmental measures for reduction of chemical inputs in Tuscany. Natural Resources Research 28 (S1): 93-110. - doi: 10.1007/ s11053-018-9398-z

Riccioli F, Castiglione F, Casini L, El Asmar JP, Fratini R (2019b). Analysis of ecosystem services provided by forests: a case study in Southern Italy. Scienze Regionali, vol. 18 (3/2019), pp. 447-464.

Riccioli F, Marone E, Boncinelli F, Tattoni C, Rocchini $D$, Fratini $R$ (2019c). The recreational value of forests under different management systems. New Forests 50 (2): 345-360. - doi: 10.100 7/s11056-018-9663-3

Riccioli F, Fratini R, Marone E, Fagarazzi C, Calderisi M, Brunialti G (2020). Indicators of sustainable forest management to evaluate the socio-economic functions of coppice in Tuscany, Italy. Socio-Economic Planning Sciences 70: 100732. - doi: 10.1016/j.seps.2019.100732 Romano S, Fanelli L, Viccaro M, Di Napoli F, Cozzi $M$ (2015). The effects of climate change on the multifunctional role of Basilicata's forests: the effects induced on yield and $\mathrm{CO}_{2}$ absorption. In: "The Sustainability of Agro-Food and Natural Resource Systems in the Mediterranean Basin" (Vastola A eds). Springer, Cham, Switzerland, pp. 191-207. - doi: 10.1007/978-3-319-16357-4_13 Rothermel RC (1972). A mathematical model for predicting fire spread in wildland fuels. Intermountain forest and range experiment station. Research Paper INT-115, USDA Forest Service, Ogden, UT, USA, pp. 40. [online] URL: http:// books.google.com/books?id=AfyMv5NBSjoC Srivas T, De Callafon RA, Crawl D, Altintas I (2017). Data assimilation of wildfires with fuel adjustment factors in farsite using Ensemble Kalman Filtering. Procedia Computer Science 108: 1572-1581. - doi: 10.1016/j.procs.2017.05.197 Sugihara NG, Van Wagtendonk JW, Shaffer KE, Thode AE, Fites-Kaufman J (2006). Fire in California's ecosystems. University of California Press, Berkeley, CA, USA, pp. 1-568. [online] URL: http://nau.pure.elsevier.com/en/publicati ons/fire-in-californias-ecosystems

Syphard AD, Rustigian-Ramsos H, Mann M, Conlisk E, Moritz MA, Ackerly D (2019). The relative influence of climate and housing development on current and projected future fire patterns and structure loss across three California landscapes. Global Environmental Change 56: 41-55. - doi: 10.1016/j.gloenvcha.2019.03.007

Tan X, Chen S, Gan TY, Liu B, Chen X (2019). Dynamic and thermodynamic changes conducive to the increased occurrence of extreme spring fire weather over western Canada under possible anthropogenic climate change. Agricultural and Forest Meteorology 265: 269-279. - doi: 10.1016/j.agrformet.2018.11.026

Tao Z, Yan H, Zhan J (2012). Economic valuation of forest ecosystem services in Heshui watershed using contingent valuation method. Procedia Environmental Sciences 13: 2445-2450. doi: 10.1016/j.proenv.2012.01.233

Viccaro M, Caniani D (2019). Forest, agriculture, and environmental protection as path to sustainable development. Natural Resources Research 28: 1-4. - doi: 10.1007/s11053-019-09497-2 Viccaro M, Cozzi M, Fanelli L, Romano S (2019). Spatial modelling approach to evaluate the economic impacts of climate change on forests at a local scale. Ecological Indicators 106: 105523. - doi: 10.1016/j.ecolind.2019.105523

Zandersen M, Tol RSJ (2009). A meta-analysis of forest recreation values in Europe. Journal of Forest Economics 15 (1-2): 109-130. - doi: 10.1016/ j.jfe.2008.03.006

Zhou T, Ding L, Ji J, Li L, Huang W (2019). Ensemble transform Kalman filter (ETKF) for largescale wildland fire spread simulation using FARSITE tool and state estimation method. Fire Safety Journal 105: 95-106. - doi: 10.1016/j.fire saf.2019.02.009 